\title{
OPTIMIZATION OF CAISSON BREAKWATER SUPERSTRUCTURE GEOMETRY USING A 2DV RANS-VOF NUMERICAL MODEL
}

\begin{abstract}
Shubhra Misra ${ }^{1}$, N. S. Muthukumar ${ }^{2}$, Atilla Bayram ${ }^{3}$,and Fengyan Shi ${ }^{4}$
This paper demonstrates that numerical modeling tools such as a RANS-VOF model can be applied confidently to reduce the level of uncertainty from empirical guidance and provide for a deterministic quantification of the hydraulic response associated with any arbitrary Caisson breakwater superstructure geometry. The RANS-VOF model used for this paper is first satisfactorily validated against laboratory measurements (surface elevation, overtopping and pressure) of a caisson breakwater on a rubble-mound foundation and then applied to several prototype caisson breakwater superstructure geometries. Numerical simulations presented in this paper for prototype geometries demonstrate that curved/inclined parapets, when compared with vertical face caisson breakwaters with the same crest elevation, can lead to large increases in overtopping as well as downward forces. Expectedly, the landward forces are reduced by the implementation of a curved or recessed and inclined parapet when compared to a caisson with a completely vertical face. During large overtopping events, the model results show that much larger short-duration seaward loads can be generated for curved and inclined superstructures when compared to vertical face geometries. This is in general agreement with previous laboratory experiments as well as field observations of seaward caisson sliding and failure resulting from large overtopping events. Further, numerical experiments indicate that the overtopping response of a superstructure can vary noticeably due to small changes in the recessed length of an inclined or curved parapet. The numerical model also easily provides for the quantification of the variation of instantaneous and peak overtopping discharges along the crest of the caisson superstructure, and which can provide for useful guidance in the design of various crest infrastructure components, such as drainage systems, flow deflectors, wave power devices etc.
\end{abstract}

Keywords: RANS-VOF numerical modeling; Wave-structure interaction; Caisson breakwater; Wave overtopping; Wave forces

\section{INTRODUCTION}

Caisson breakwaters are frequently used to shelter moored vessels from wave action in ports, harbours and marine terminals, to protect coastal communities from flooding, and even to mitigate the effects of coastal erosion. In the last few decades, caisson breakwaters have seen a resurgence especially due to the increasing need for breakwaters in deeper waters which makes caisson breakwaters attractive when compared with rubble mound breakwaters from a cost, design and constructability perspective. Innovations in design and construction techniques continue to be implemented to address this growing need, but also to learn from and avoid the mistakes that led to catastrophic failures experienced by caisson breakwaters in the 1970s and 1980s (Oumercai et al., 2001). The design, reliability, cost and performance requirements for a caisson breakwater have to take into account structural, geotechnical and hydraulic reponses of the breakwater. In terms of hydraulic response, wave overtopping is one of the most critical performance indicators of a caisson breakwater. Overtopping not only affects the breakwater's functional efficiency but also plays a role in its own structural damage state and stability. It is the superstructure geometry of the caisson breakwater which dominantly affects the overtopping response. On the other hand, the hydrodynamic forces due to wave interactions with the breakwater are a significant component in determining the overall stability and damage state of the breakwater through its design life.

A large amount of work has been done in the past to characterize the hydraulic response of caisson breakwaters addressing both overtopping and wave forces. These studies have incorporated deterministic and probabilistic approaches and refinements/corrections/adjustments to empirical guidance account in order to specifically account for the varying impacts due to different superstructure parapet geometries (Goda, 2000; Juhl and van der Meer, 1992; Franco et al., 1994; Takahashi et al., 1994, Oumeraci et al., 2001 (PROVERBS), Eurotop (2007) and others). However, the somewhat limitless range and choice of superstructure geometries that are available to a designer,

\footnotetext{
${ }^{1}$ Ben C. Gerwick, Inc. (A COWI Company), 11000 Richmond Avenue, Houston, TX, 77042, USA (shmi@gerwick.com)

2 PBS\&J, 1250 Wood Branch Park Drive, Houston, TX 77079, USA

${ }^{3}$ Halcrow, Inc., 22 Cortlandt St, New York, 10007, USA

${ }^{4}$ Center for Applied Coastal Research, University of Delaware, Newark, DE, 19716, USA
} 
which critically affects the overall hydraulic response of the breakwater, makes it inevitable that specific guidance for a particular superstructure geometry will always be lacking, and at the very least, be underscored by a large band of uncertainty. This uncertainty in turn translates to unnecessary conservatism in deterministic guidance. Further, empirical formulae used to estimate wave overtopping and wave forces on a caisson breakwater typically provide estimates for maximum wave forces under a quasi-static assumption and do not account for the impulsive landward and seaward loads due to wave impacts that can exceed hydrostatic forces by an order of magnitude.

In this paper, we contend that numerical modeling tools can be applied with confidence towards not only narrowing the level of uncertainty as inherent in the application of available empirical guidance (for the deterministic prediction of overtopping response and wave forces for a caisson breakwater), but as a cost-effective and efficient alternative to laboratory physical modeling experiments towards preliminary optimization of caisson superstructure geometries. In section 2, we describe one such numerical modeling tool, followed by the model validation and application to two typical caisson superstructure geometries in section 3 and section 4 , respectively. In section 5 , we describe some additional numerical experiments to further investigate the sensitivity of the superstructure geometry to its hydraulic response, followed by some conclusions in section 6. A discussion is presented at the end of the paper regarding future work.

\section{RANS-VOF NUMERICAL MODELS}

Numerical models of fluid/wave-structure interactions are increasingly becoming a viable tool in furthering our understanding of the complicated phenomena that govern the hydraulic response of breakwaters, including effects of permeability (Losada, 2003). These include Lagrangian models with particle-based approaches such as the Moving Particle Semi-Implicit method (Koshizuka et al., 2005) and Smooth Particle Hydrodynamics (SPH) (Dalrymple et al., 2009). It is noted here that new SPH models are just becoming available that not only model the fluid phase of the interaction but the movements of the caisson breakwater itself when subject to wave loads (Rogers et al. 2010). For reasons ranging from computational efficiency to an accurate representation of the physical processes, Reynold Averaged Navier Stokes-Volume Of Fluid (RANS-VOF) models such as those developed by Lara et al. (2008) and Shi et al. (2004) have become an attractive choice of to model wave interactions with both solid as well as porous structures.

The RANS-VOF models noted above have been developed by implementing various extensions to the RIPPLE model (Kothe et al, 1991; originally designed to provide a solution of two-dimensional versions of the Navier-Stokes equations in a vertical plane with a free surface.), making it specifically applicable to the study of wave interactions with coastal structures. The models solve the twodimensional vertical (2DV) RANS equations and the $\mathrm{k}-\varepsilon$ equations for the turbulent kinetic energy (k), and the turbulent dissipation rate $(\varepsilon)$. Various other turbulence models have also been successfully implemented. A nonlinear algebraic Reynolds stress model is used to relate the Reynolds stress tensor and the strain rate of mean flow. The free surface movement is tracked by the Volume of Fluid (VOF) method. The flow inside the porous media is solved through the resolution of the Volume-Averaged Reynolds Averaged Navier-Stokes (VARANS) equations, which are derived by integrating the RANS equations over a control volume. In the VARANS equations, the interfacial forces between the fluid and solids are modeled according to the extended Forchheimer relationship, in which both linear and nonlinear drag forces are included in the equations. An internal wavewaker based on a source function approach lends the models the ability to generate a wide range of desired wave conditions.

The models have undergone various validation procedures over the last decade or so, including wave interactions with low-crested structures (Losada et al., 2005), wave breaking on permeable slopes (Lara et al., 2006), surf zone hydrodynamics on natural beaches (Torres-Freyermuth et al., 2007), overtopping on rubble mound breakwaters and low-mound breakwaters including caissons on rubble mound foundations (Lara et al., 2008), and even ported caisson breakwaters (Shi et al. 2004). In this paper, we use the RANS-VOF model developed by Shi et al. (2004).

\section{NUMERICAL MODEL VALIDATION}

To validate the numerical model, we compare the numerical model results against measurements for laboratory experiments (1:20 scale) conducted by Lara et al. (2008) for an impermeable caisson 
breakwater on a rubble-mound foundation. The breakwater geometry is shown in Figure 1, and details of the experimental set up and wave conditions can be found in Lara et al. (2008). As we are primarily interested in the numerical model's performance with regard to wave overtopping and wave forces, we first compare the model results with surface elevation and pressure as measured by several wave gages and pressure transducers as deployed in the laboratory experiments. The numerical model is initialized by measured time series of surface elevation near the wavemaker. No other calibration or parameter tuning has been performed, and default values as recommended by Lara et al. (2008) have been retained for the numerical model parameters.

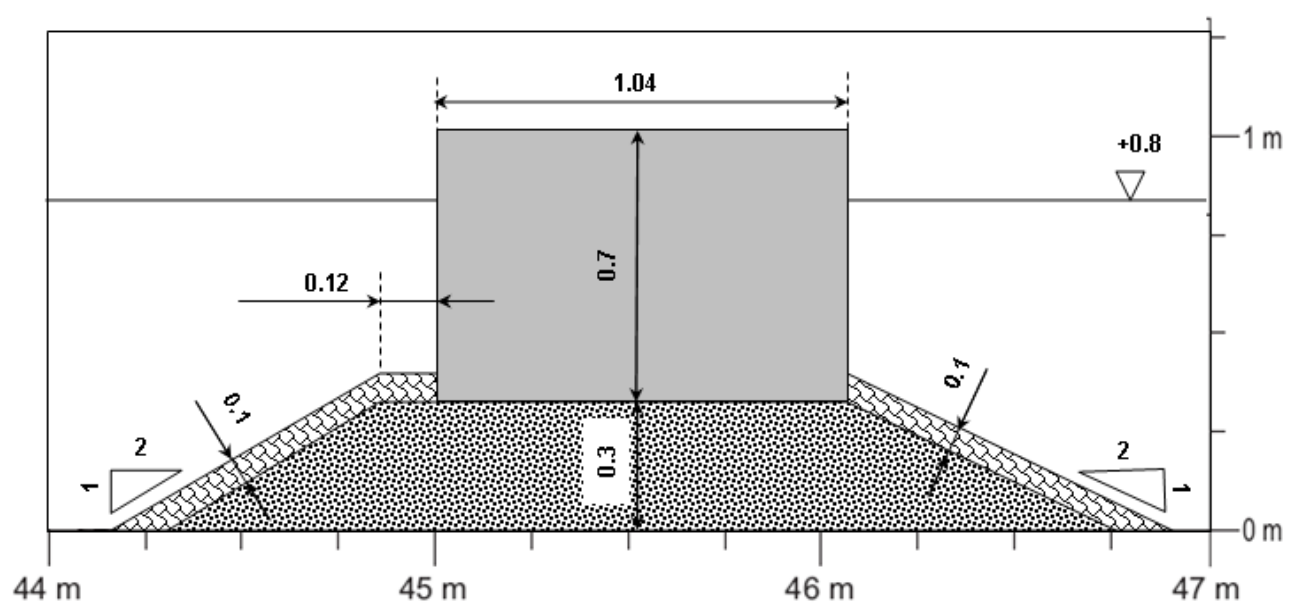

Figure 1. Experimental set up for impermeable caisson breakwater on rubble mound foundation (adapted from Lara et al. 2008)

Figure 3 shows a comparison of modeled and measured surface elevations at several wave gage locations (shown in Figure 2), including locations along the crest of the caisson to measure overtopping. The comparisons are reasonable, especially considering that no calibration attempts were made beyond using the default parameters suggested by Lara et al. (2008). In particular, the numerical model picks up the episodic overtopping events as captured by the wave gages located along the crest of the caisson (WG 12 and WG 13). Figure 4 shows a comparison of the measured and modeled cummulative overtopping at the WG 11 gage location, i.e., near the front end of the caisson crest.

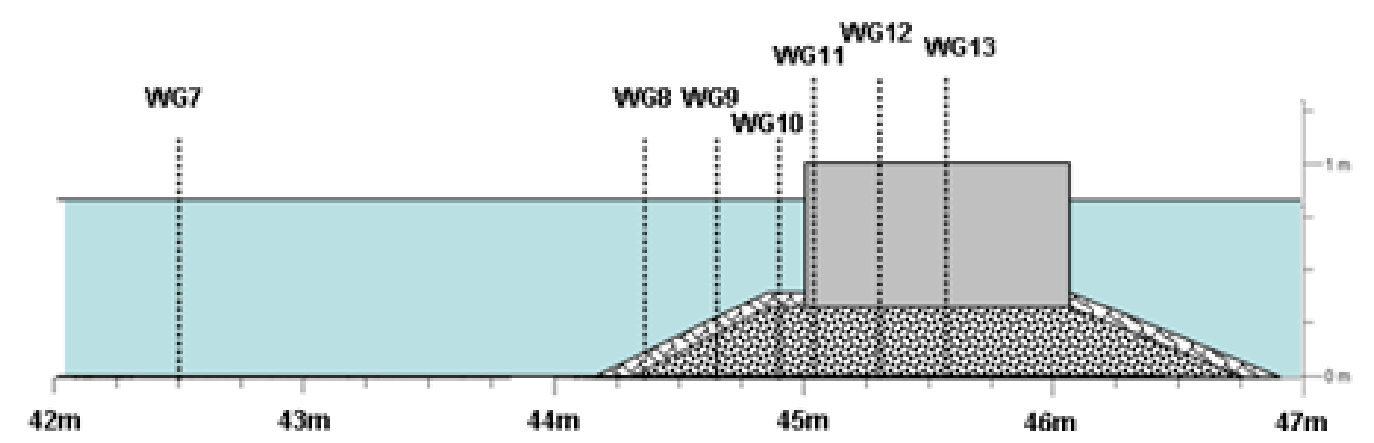

Figure 2. Experimental set up for impermeable caisson breakwater on rubble mound foundation (adapted from Lara et al. 2008) 

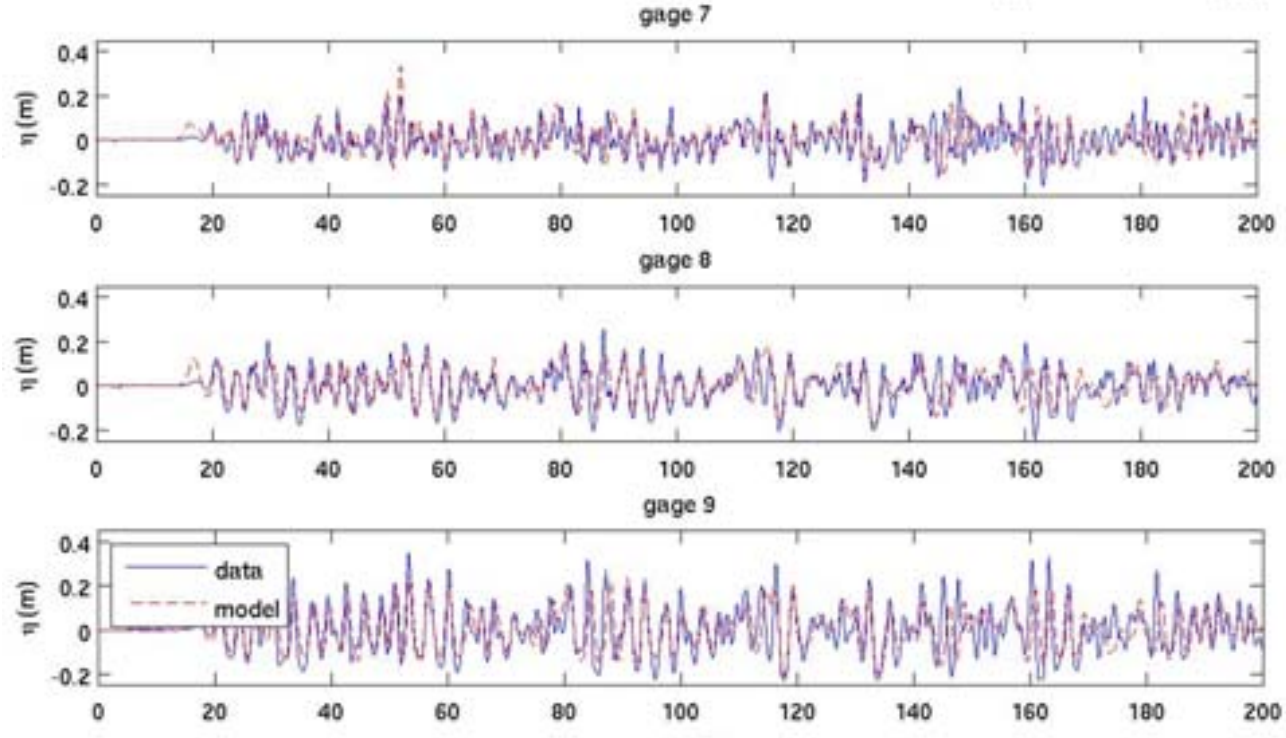

gage 10

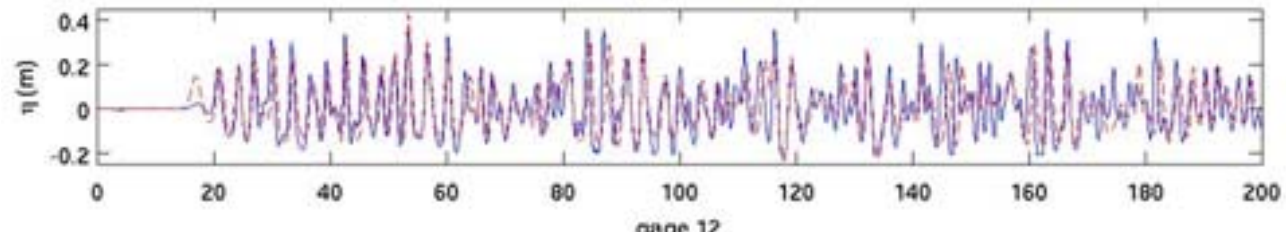

gage 12
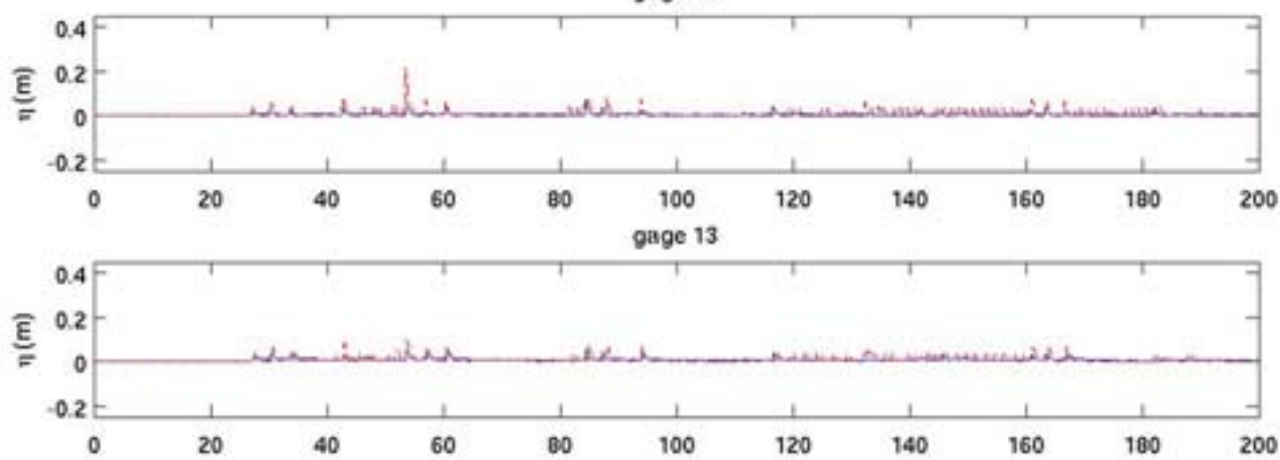

Figure 3. Comparison of surface elevation between numerical model (red dashed line) and experimental observations (blue solid line) for wave gage locations shown in Figure 2. Horizontal axis is time (s).

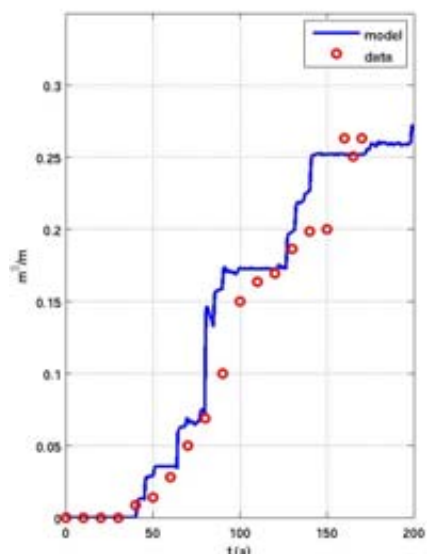

Figure 4. Comparison between modeled (solid blue line) and measured (red circles) cummulative overtopping over crest of caisson (at WG 11 - see Figure 2 for gage locations and annotation). 

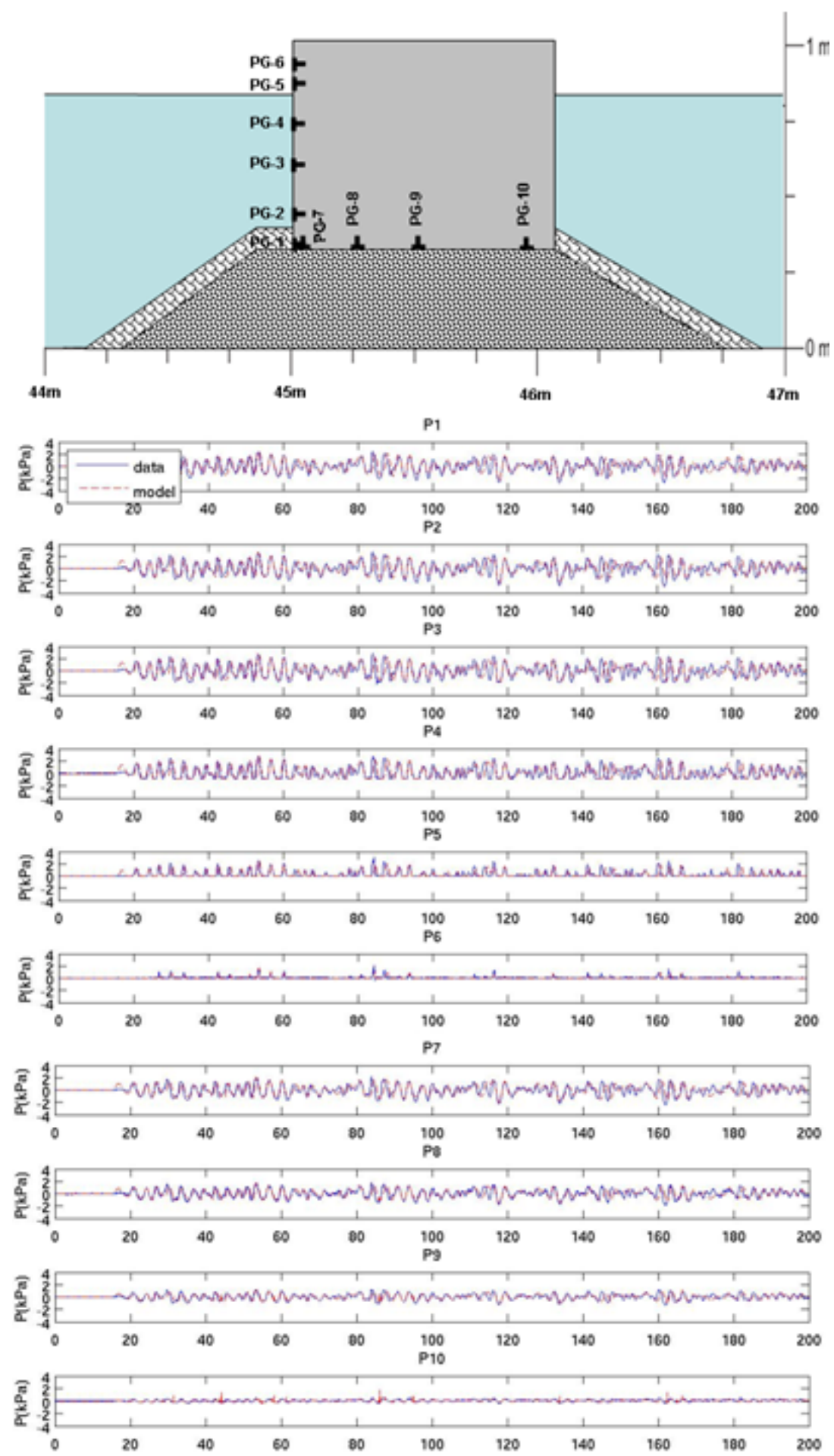

Figure 5. Comparison of total pressue between numerical model (red dashed line) and experimental observations (blue solid line) at pressure gage locations shown in top panel

Figure 5 shows a comparison of the modeled (red dashed line) and measured (solid blue line) pressure at various locations along the front face of the caisson as well as the bottom of the (impermeable) caisson on top of the (permeable) rubble mound foundation. The comparisons are excellent. In particular, the numerical model appears to be faithfully modeling the flow through the permeable rubble mound foundation which is evidenced by the good comparisons of pressure found at the interface between the caisson and the rubble mound foundation. 
The comparisons of model results with laboratory measurements of surface elevation, overtopping and pressure provide confidence in the subsequent application of the model to prototype scale, and which is described in the next section. It is noted here in passing that one of the advantages of the numerical model over laboratory experiments is that the numerical model does not suffer from any scale effects and limitations are due only to the nature and extent of physical processes represented in the model, and the accuracy to which they are solved numerically.

\section{VERTICAL FACE VIS CURVED RECESSED PARAPET SUPERSTRUCTURE}

For an actual ongoing project in the Mediterranean sea (details of the project are confidential), a caisson breakwater option was determined to be a potentially viable alternative to rubble mound breakwaters, and two superstructure geometries were considered. Based on previous experience (e.g., Van der Meer et al., 1994), it was anticipated that the superstructure geometry in the form of a curved recessed parapet may afford better stability with regard to wave forces. Accordingly, two superstructure geometries were designed and investigated numerically - one with a curved and recessed parapet after the Civitavecchia breakwater (Figure 6) and the other with a completely vertical face with the same crest elevation. Both were founded upon a crushed rock foundation (porosity $=0.4$ ) dredged below the native seabed. The design wave conditions were a significant wave height of $\mathrm{H}_{\mathrm{m} 0}=4.2 \mathrm{~m}$ and a peak wave period of $T_{p}=13.4 \mathrm{~s}$. The numerical model was then set up to investigate the comparative hydraulic response of the vertical face and curved and recessed parapet superstructure geometries for the caisson (Figure 7). A mean JONSWAP spectral shape with peak enhancement factor of 3.3 was used for the incident wave conditions that were generated by the internal wavemaker in the model. Sponge layers were included at both lateral ends of the domain to absorb waves and avoid spurious wave reflections back into the domain. The total simulation time duration for each model run was 7200s, i.e., approximately 537 peak wave periods.

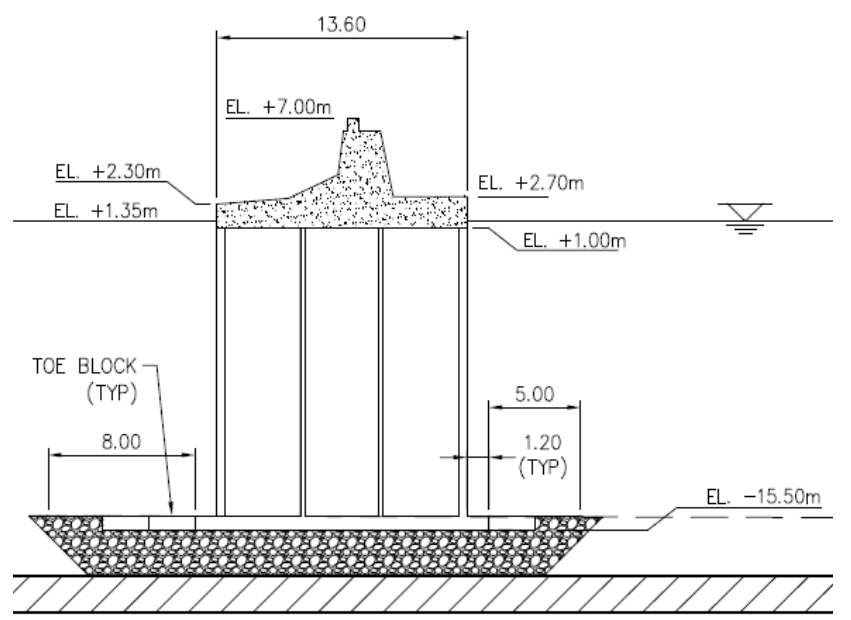

Figure 6. Caisson breakwater, with superstructure geometry adopted after the Civitavecchia breakwater in the form of a curved and recessed parapet.

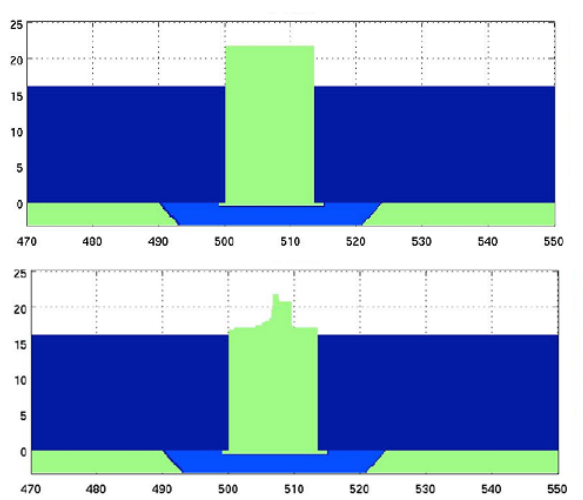

Figure 7. Numerical model set up for the vertical face (top panel) and curved and recessed parapet (bottom panel) superstructure caisson geometries. The wavemaker is to the left. 
Figure 8 shows a comparison of the instantaneous snapshots of kinetic energy for the two model simulations, and illustrates the increased overtopping that occurs for the curved and recessed parapet compared to that for the vertical face, which is expected due to the increased run-up facilitated by the curved and recessed parapet geometry. This is further confirmed by a comparison of the cummulative overtopping for the two superstructure geometries as shown in Figure 9. Figure 10 shows the location along the crest where overtopping is calculated for both superstructures.

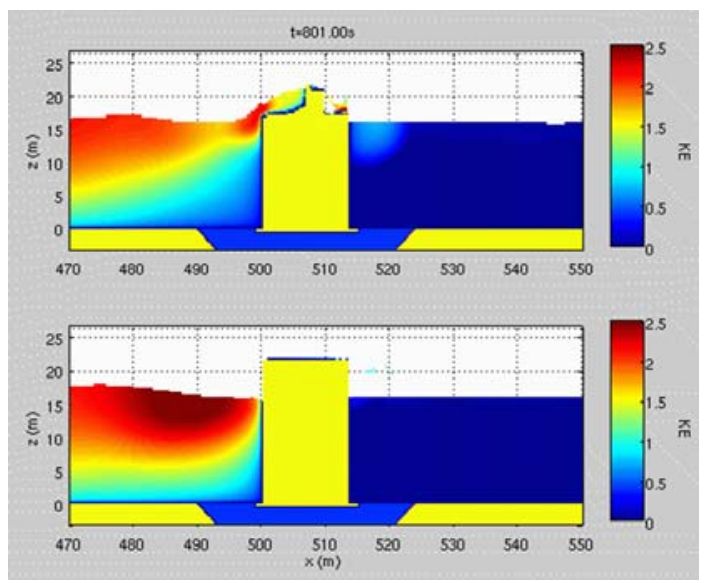

Figure 8. Comparison of instantaneous $(t=801 \mathrm{~s})$ snapshots of kinetic energy for curved and recessed parapet (top panel) and vertical face (bottom panel) superstructure geometry.

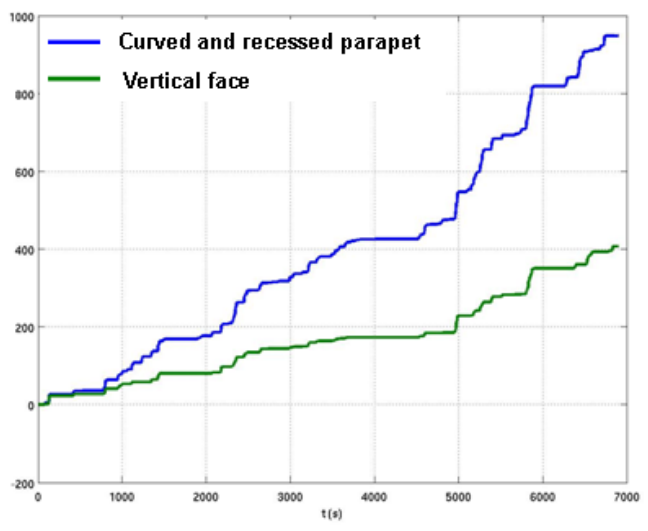

Figure 9. Comparison of cummulative overtopping for curved recessed parapet (blue line) and vertical face (green line) superstructures.
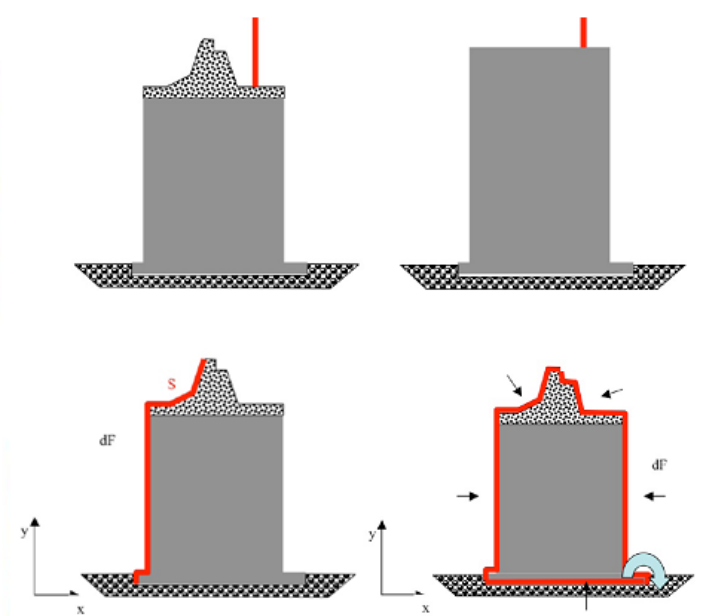

Figure 10. Location and geometrical definitions for calculation of overtopping (top panel), forces and moments (bottom panel). 
Next, a comparison of landward forces and moments is made for a typical segment of the simulation including a large overtopping event (at approximately $t=800 \mathrm{~s}$ ), where the forces and moments are calculated from the pressure as shown in Figure 9. Clearly, and as expected, the curved and recessed parapet superstructure geometry reduces the total (on the entire front face of the caisson; see left panel of Figure 11) landward forces and moments when compared to the vertical face. This reduction for the curved and recessed parapet occurs primarily because the wave force on the vertical part of the front face is out of phase with the wave force on the superstructure parapet, but also because part of the landward force on the front face of the caisson also gets directed downward for a curved recessed parapet.
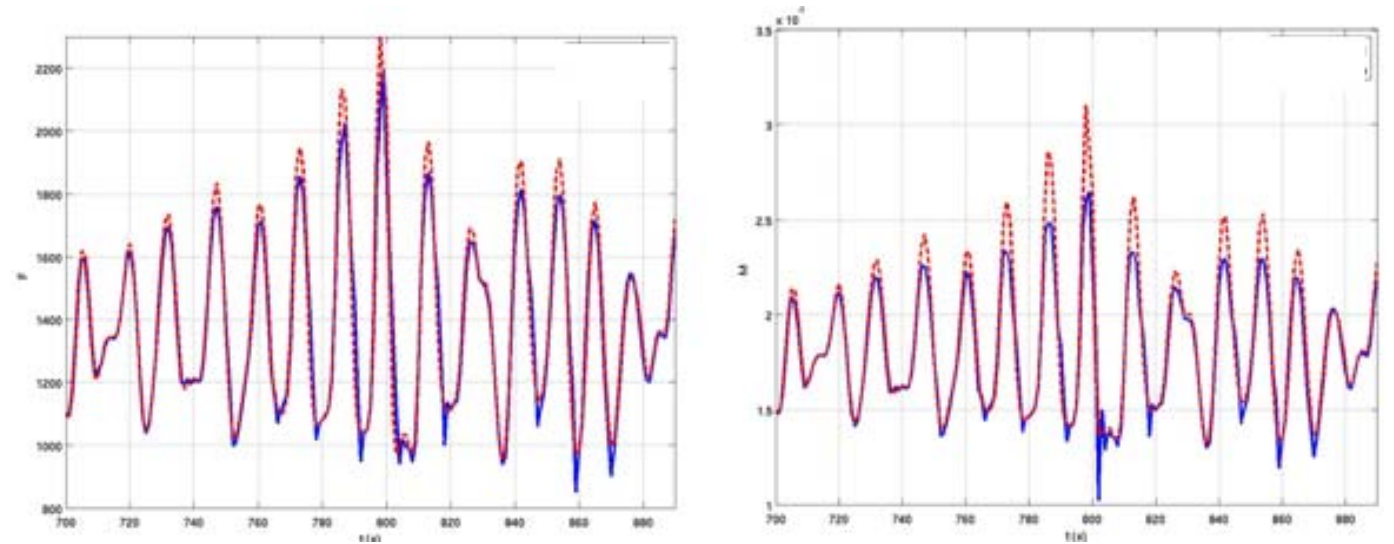

Figure 11. Comparison of total (on the entire front face of the caisson) landward forces (left panel) and landward moments (right panel) for caisson with vertical face (red dashed line) and caisson with curved and recessed parapet (blue solid line).

The comparison of seaward forces (Figure 12) on the other hand shows a rather surprising feature of the relative response of the two superstructure geometries and which is repeated after each large overtopping event during the simulation. There is a much larger total (on the entire rear face of the caisson) seaward force (and associated seaward moment) experienced by the curved recessed parapet compared to that for the vertical face superstructure. To better understand the nature of this difference, and to explain the much larger force experienced by the curved and recessed parapet caisson, we look at Figure 13, which shows the instantaneous snapshots of pressure at the corresponding time instant in the simulation.
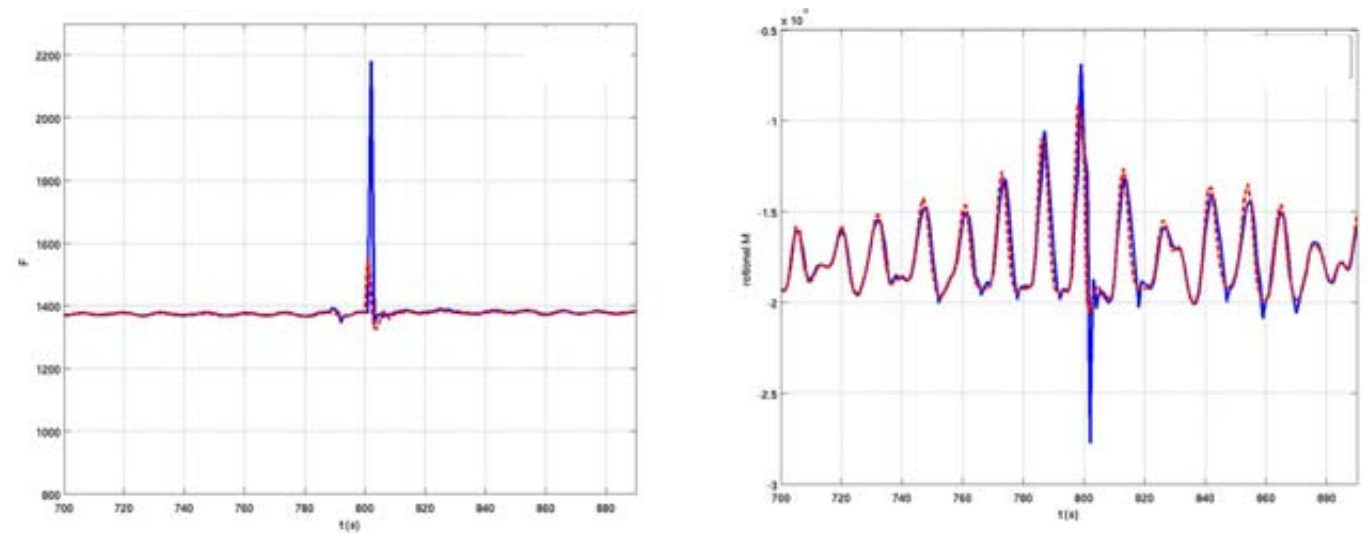

Figure 12. Comparison of seaward forces (left panel) and seaward moments (right panel) for caisson with vertical face (red dashed line) and caisson with curved and recessed parapet (blue solid line).

As can be seen from Figure 13, after a large overtopping event, and once the water has receded from the front face of the superstructure, the hydrodynamic pressure at the rear side of the caisson with a curved recessed parapet is much larger than that for a vertical face caisson, and as this is larger than the pressure at the front face of the caisson, it leads to a correspondingly larger net seaward force (and moment). This accentuation of seaward force after a large overtopping event, although for a very short time duration, has been noticed in the laboratory experiments conducted by Walkden et al. (2001). In 
fact, and even though there are differences in the superstructure geometry, Figure 5(d) of Walkden et al. (2001) is qualitatively similar to the top panel in Figure 13. The sudden increase in seaward force happens both due to the entrapment of air pockets at the rear side of the caisson during the plunge of the overtopping jet, as well as due to the sudden increase in water level at the rear face while water runs down the front face. The "seaward impact loading" induced by wave overtopping is believed to be the cause of seaward-directed sliding and overturning failures of caisson breakwaters in the field as well (Walkden et al, 2001; Agerschou et al. 2004).
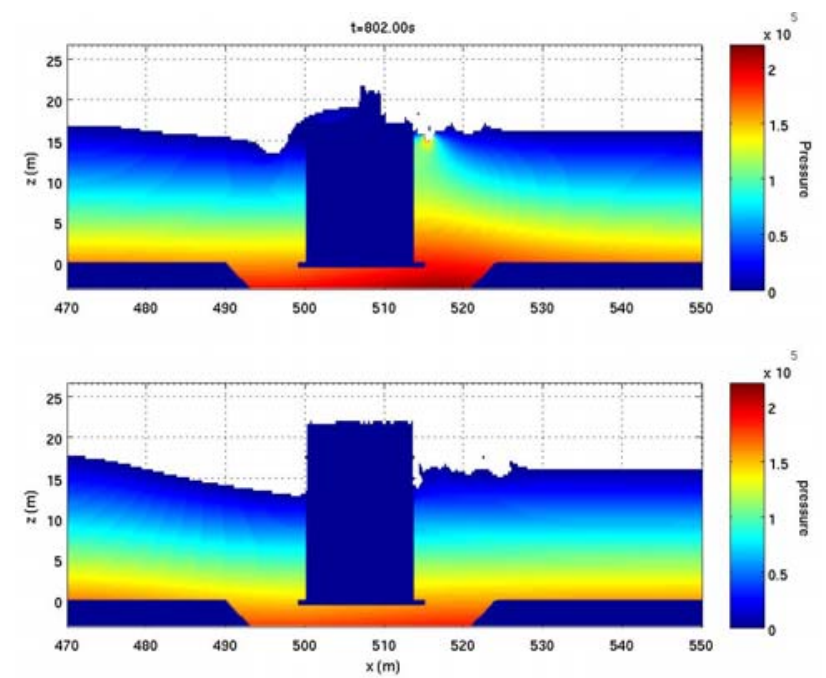

Figure 13. Comparison of pressure for caisson with vertical face (bottom panel) and caisson with curved and recessed parapet (top panel) after a large overtopping event.

Next, the model results are compared to established empirical formula which are typically applied during the design process. Figure 14 shows a comparison of the numerical model results with several empirical formulae for the dimensionless mean overtopping rate for the vertical face caisson. Quite clearly, for the given dimensionless freeboard, there is a wide range of uncertainty in the available empirical guidance for mean overtopping rate (ranging from $13.5 \mathrm{l} / \mathrm{s} / \mathrm{m}$ to $81 \mathrm{l} / \mathrm{s} / \mathrm{m}$ - a factor of six difference between the lowest and highest empirical values!). It is somewhat comforting to note that only the deterministic formula in Eurotop (2007) provides for a conservative result when compared to the numerical model result. There are no empirical formula which provide estimates of overtopping for the specific curved recessed geometry.

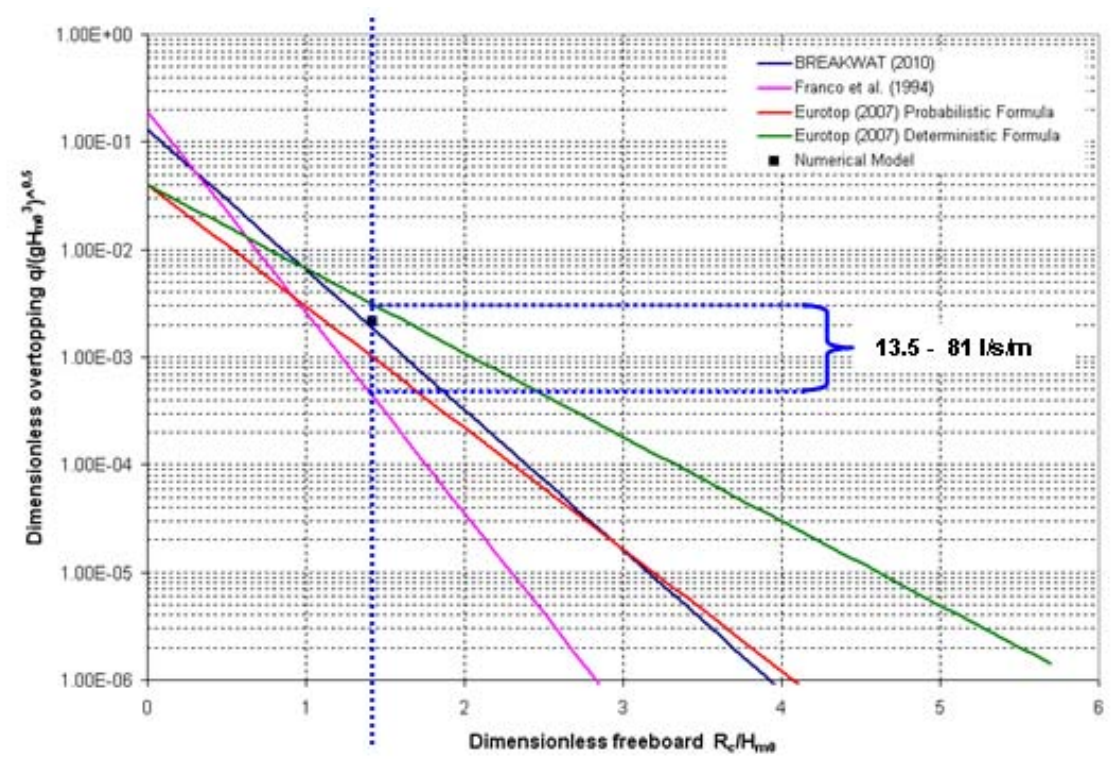

Figure 14. Comparison of numerical model result for mean overtopping with empirical formulas. 
Table 1 shows a comparison of the hydraulic performance indicators for the two caisson superstructure geometries as obtained from the entire numerical model simulation period of 7200 s, including the mean overtopping rate, the net landward force, the downward force and the uplift force. A percentage reduction is also provided to get an idea of the relative difference between the two geometries; a positive percentage reduction indicates smaller values for the curved and recessed parapet compared to the vertical face caisson, and vice versa.

Table 1. Comparison of mean overtopping rate and forces between caisson with vertical face and with curved recessed parapet

\begin{tabular}{|c|c|c|c|c|}
\hline \multicolumn{2}{|c|}{} & Vertical Face & Curved Recessed Parapet & $\begin{array}{c}\text { Percentage } \\
\text { Reduction }\end{array}$ \\
\hline Mean Overtopping Rate (L/s/m) & 59 & 137 & -132 \\
\hline \multirow{2}{*}{ Forces } & $\begin{array}{c}\text { Net Landward Force } \\
\left(F_{-} \mathbf{0 . 4 \% , ~ k N / m )}\right.\end{array}$ & 1017 & 836 & 18 \\
\cline { 2 - 5 } & $\begin{array}{c}\text { Uplift Force (F_0.4\%, } \\
\text { kN/m) }\end{array}$ & 3130 & 3097 & 1 \\
\cline { 2 - 5 } & $\begin{array}{c}\text { Downward Force } \\
\left(F_{-} \mathbf{0 . 4} \%, \mathbf{k N} / \mathrm{m}\right)\end{array}$ & 292 & 380 & -30 \\
\hline
\end{tabular}

As expected, the net landward force is reduced (approximately $20 \%$ ) by the implementation of the curved and recessed parapet superstructure, whereas the downward force is increased. Depending on the severity of impact, downward directed impact forces may cause damage and collapse of the crest/deck slab of the caisson, but it may also contribute to the overall vertical stability of the caisson by reducing the net uplift force. Noticeably, the mean overtopping rate for the curved recessed parapet is more than double of that for the vertical face caisson. As discussed earlier, large overtopping events were found to cause short-duration but large seaward forces. These impulsive seaward forces, if they occur frequently, are known to cause seaward failures in caisson breakwaters. The final design was chosen based on the above observations as well as cost and constructability considerations.

\section{FURTHER NUMERICAL STUDIES}

The significant differences in the hydraulic response of the vertical face and curved recessed parapet motivated some further, and separate, numerical investigations of more simplified geometries in the form of a) a vertical face, b) an inclined parapet and c) an inclined parapet with a recess of $1 \mathrm{~m}$ from the front face of the caisson. These superstructure geometries are shown in Figure 15. The crest elevation of all three caisson breakwaters was the same. The still water depth was fixed at $+16 \mathrm{~m}$ for all simulations, and the design wave conditions were $\mathrm{H}_{\mathrm{m} 0}=4.7 \mathrm{~m}$ and a peak wave period of $\mathrm{T}_{\mathrm{p}}=13.4 \mathrm{~s}$. A mean JONSWAP spectrum with a peak enhancement factor of 3.3 was used to represent the incident design wave conditions. A crushed rock foundation with a porosity of 0.4 was designed as the base of the caisson breakwater.

(a)

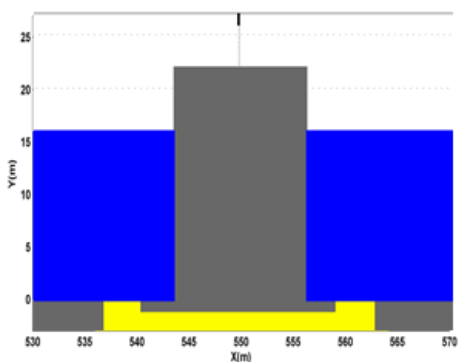

(b)

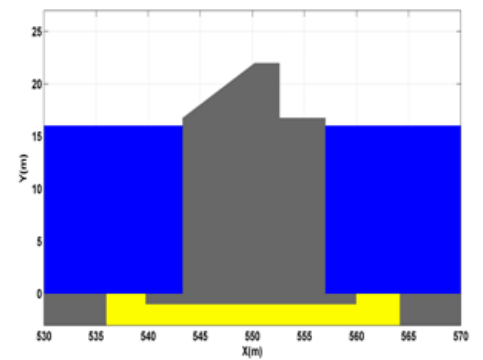

(c)

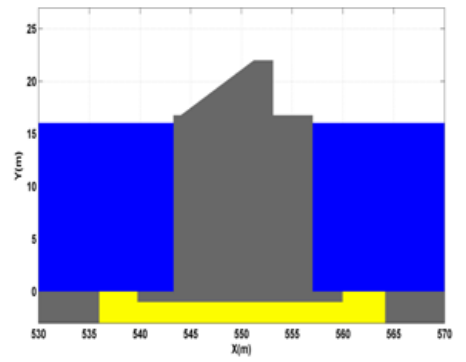

Figure 15. Caisson superstructure geometries tested in the numerical model - (a): Vertical face, (b) Inclined parapet (No recess), and (c) Recessed and inclined parapet 
For each caisson geometry, three simulations were conducted with three different crest elevations (Crest freeboard $=+6 \mathrm{~m}$ (Run 1), $+5 \mathrm{~m}$ (Run 2) and $+4 \mathrm{~m}$ (Run 3)), but with the same water level and wave conditions. Figure 16 shows the location (red vertical line) along the crest of the three caisson geometries used for the calculation of cummulative overtopping. The red circle in the rightmost panel highlights the small amount of recess, i.e., a length of $1 \mathrm{~m}$, that was implemented for the recessed inclined parapet. Figure 17 shows the comparison of cummulative overtopping for the three caisson superstructure geometries. As expected, the overtopping is the lowest for the vertical face caisson. It is also clear that even a small $(1 \mathrm{~m})$ recess to the incline of the front face of the caisson superstructure leads to a noticeable increase in overtopping when compared to the no-recess geometry.
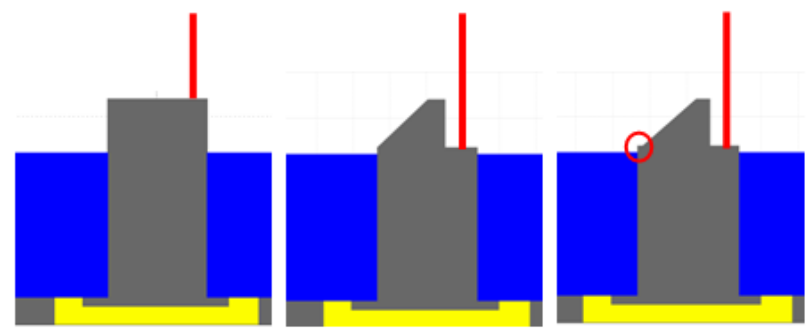

Figure 16. Location (red vertical line) along crest of caissons for calculation of cummulative overtopping (red circle highlights the $1 \mathrm{~m}$ recess for the inclined and recessed parapet superstructure geometry)

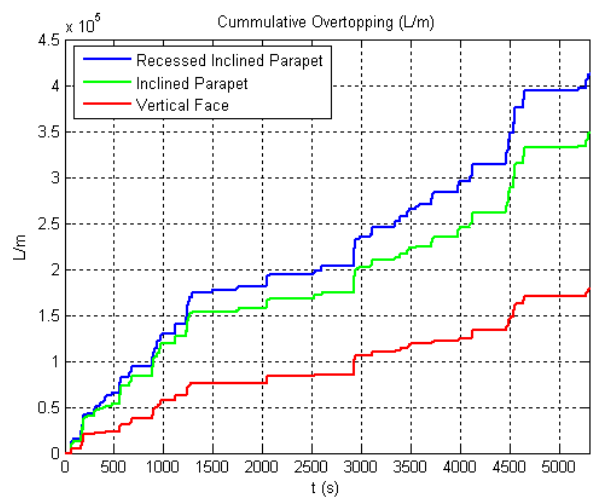

Figure 17. Comparison of cummulative overtopping rate between various superstructure geometries

\section{CONCLUSIONS AND FUTURE WORK}

The superstructure geometry of a caisson breakwater is known to critically affect its hydraulic response and its desired performance, both from a functional and stability/safety points of view, due to the dominant role played by wave overtopping and hydrodynamic wave forces. As the choice of a particular superstructure geometry in optimizing a caisson breakwater's hydraulic response is casespecific and therefore somewhat arbitrary, it obvious that deterministic guidance for a specific superstructure geometry will always be lacking. Even then, a level of uncertainty is unavoidable due to the scatter resulting from the compilation of various laboratory and field data sets (for specific geometries) that form the basis for the empirical guidance. In such a scenario, this paper demonstrates that numerical modeling tools such as a RANS-VOF model can be applied confidently to reduce the level of uncertainty and provide for a deterministic quantification of the hydraulic response associated with any arbitrary superstructure geometry. The RANS-VOF model used for this paper is first satisfactorily validated against laboratory measurements (surface elevation, overtopping and pressure) of a caisson breakwater on a rubble-mound foundation and then applied to several prototype caisson breakwater superstructure geometries.

Functional (overtopping) performance and stability (sliding/overturning) requirements can be opposing constraints towards optimization of the superstructure geometry, and numerical simulations presented in this paper for prototype geometries demonstrate that curved/inclined parapets, when compared with 
vertical face caisson breakwaters with the same crest elevation, can lead to large increases in overtopping as well as downward forces. Expectedly, the landward forces are reduced by the implementation of a curved or recessed and inclined parapet when compared to a caisson with a completely vertical face. During large overtopping events, the model results show that much larger short-duration seaward loads can be generated for curved and inclined superstructures when compared to vertical face geometries. This is in general agreement with previous laboratory experiments as well as field observations of seaward caisson sliding and failure resulting from large overtopping events. The physical processes governing these short-duration seaward loads are a combination of trapped air pockets at the rear of the caisson during the plunge of the overtopping jet, and the relative rise in water level on the rear side as the water recedes and runs down the front face of the caisson superstructure. Further, numerical experiments indicate that the overtopping response of a superstructure can vary noticeably due to small changes in the recessed length of an inclined or curved parapet. The numerical model also easily provides for the quantification of the variation of instantaneous and peak overtopping discharges along the crest of the caisson superstructure, and which can provide for useful guidance in the design of various crest infrastructure components, such as drainage systems, flow deflectors, wave power devices etc.

With the increasing efficiency of computational resources, the computational burden for RANS-VOF models are steadily decreasing, but are still not insignificant. However, as statistically averaged parameters such as mean overtopping and "significant” forces are good indicators of performance for the preliminary screening of alternative geometries during the conceptual design stage, alternative simulation techniques can be applied. For e.g., instead of simulating a single continuous incident time series, one can split up the incident wave forcing into several overlapping segments which can then be run in parallel on multiple cores or even separate computers. These can then be "stitched" together to provide robust statistical measures of the hydraulic response of a given superstructure geometry, and which is anticipated to be quantitatively similar to the results from a single continuous simulation.

Finally, it is worth mentioning that examining the dynamical role of air in the impulsive seaward loads generated after large overtopping events, the movements of the caisson itself and the feedback with the fluid phase, the role of wave obliquity etc. call for more sophisticated numerical models, but which are fast becoming increasingly viable (Bozorgnia et al. 2010; Rogers et al, 2010; Dalrymple et al, 2010).

\section{ACKNOWLEDGMENTS}

The authors gratefully acknowledge the useful comments by Prof. Leopoldo Franco with regard to design of caisson superstructures.

\section{REFERENCES}

Agerschou, H., Dand, I., Ernst, T., Ghoos, H., Jensen, O. J., Korsgaard, J., Land, J. M., McKay, T., Oumeraci, H., Petersen, J. B., Runge-Schmidt, L. and Svendsen, H. (2004) Planning and design of ports and marine terminals, $2^{\text {nd }}$ Edition, Thomas Telford

Bozorgnia M., Lee J-J., Raichlen F., (2010), Wave-structure interaction: Role of entrapped air on wave impact \& uplift forces, Proc. $32^{\text {nd }}$ ICCE, Shanghai, China, June 30 - July 5, 2010, ASCE

Dalrymple, R.A., M. Gómez-Gesteira, B.D. Rogers, A. Panizzo, S. Zou, A.J.C. Crespo, G. Cuomo, and M. Narayanaswamy. (2009), Smoothed Particle Hydrodynamics for Water Waves, in Advances in Numerical Simulation of Nonlinear Waves, Q.Ma, ed., World Scientific Press, ISBN 981-283-649-7.

Dalrymple, R., Herault, A. and Bilotta, P., (2010) GPU-accelerated SPH model for water waves and other free surface flows, Proc. $32^{\text {nd }}$ ICCE, Shanghai, China, June 30 - July 5, 2010, ASCE

EurOtop (2007) Wave overtopping of sea defenses and related structures: assessment manual, Die Kuste, Archive for research and technology of the North sea and Baltic coast.

Franco, L., de Gerloni, M. \& van der Meer, J.W. (1994) Wave overtopping on vertical and composite breakwaters. Proc 24 th. Int Conf Coastal End., Kobe, ASCE 
Goda, Y. (2000) Random seas and design of maritime structures. University of Tokyo. ISBN 981023256X, 433p.

Juhl, J. and Van der Meer, J. W. (1992) Quasi-static wave forces on vertical structures, reanalysis of data at Danish Hydraulic Institure and Delft Hydraulics Report. Prepared for MAST G6-S Coastal Structures.

Kothe, D. B., Mjolsness, R. C. and Torrey, M. D., (1991), RIPPLE: A computer program for incompressible flows with free surfaces, Report LA-12007, Los Alamos National Laboratory

Lara, J., Losada, I., and Guanche, R. (2008) Wave interaction with low-mound breakwaters using a RANS model. Ocean Engineering, 35, 1388-1400.

Lara, J.L., Losada, I.J., Liu, P.L.-F., 2006. Breaking waves over a mild gravel slope: experimental and numerical analysis. Journal of Geophysical Research, AGU 111, C11019. doi:10-1029/2005 JC003374.

Losada, I.J., (2003) Advances in modeling the effects of permeable and reflective structures on waves and nearshore flows. In: Chris Lakhan, V. (Ed.), Advances in Coastal Modeling. Elsevier Oceanography Series, vol. 67.

Losada, I.J., Lara, J.L., Damgaard, E., Garcia, N. (2005). Modelling of velocity and turbulence fields around and within low-crested rubble-mound breakwaters. Coastal Engineering 52, 887-913.

Oumeraci, H., Kortenhaus, O., Allsop, N.W.H, De Groot, M.B., Crouch, R.S., Vrijling, J.K., and Voortman, H.G. (2001) PROVERBS - Probabilistic Design Tools for Vertical Breakwaters. Rotterdam: Balkema, Lisse, The Netherlands, 373 pp.

Rogers, B., Dalrymple, R. A., and Stansby P. K. (2010) Simulation of caisson breakwater movement using SPH, Journal of Hydraulic Research. Vol. 48. pp 135-141.

Shi, F., Zhao, Q., Kirby, J. T., Lee, D. S., and Seo, S. N. (2004) Modeling wave interactions with complex coastal structures using an enhanced VOF model. In Proc. 29th Int. Conf. Coastal Engrng., Lisbon, September, pages 581-593.

Takahashi, S., Tanimoto, T. and Shimosako, K. (1994) Dynamic response and sliding of breakwater caissons against impulsive breaking wave forces. Proc. Intl. Workshop "Wave Barriers in Deep Waters”, Jan 10-14, 1994, PHRI, Yokosuka, Japan, pp 362-399

Torres-Freyermuth, A., Losada, I.J., Lara, J.L., 2007. Modeling of surf zone processes on a natural beach using Reynolds-averaged Navier-Stokes equations. Journal of Geophysical Research 112, C09014. doi:10.1029/2006JC004050.

Van der Meer, J., d’Angremond, K., and Juhl, J. (1994) Probabilistic calculations of wave forces on vertical structures, Proc. 24th Intl. Conf. Coastal Engineering, Kobe, Japan, ASCE

Walkden, M., Wood, D., Bruce, T., and Peregrine, D. (2001) Impulsive seaward loads induced by wave overtopping on caisson breakwaters. Coastal Engineering, 42, 257-276. 